\title{
Cholera Outbreak in the Kasaï Oriental Province, Democratic Republic of Congo (DRC), 2018: The Case Fatality Rate in Mbuji-Mayi City and in the Rural Area
}

\author{
Norbert Tanke Dongmo ${ }^{1,2, *}$, Barry Mutombo ${ }^{3,4}$, Jerome Ateudjieu ${ }^{5,6}$, Gervais Folefack Tengomo ${ }^{7}$, \\ Mavard Kwengani $^{8}$, Paulin Gabo ${ }^{7}$, Marie Claire Georgette Diwampovesa ${ }^{7}$, Laurent Akilimali ${ }^{7}$, \\ Berthe Miwanda ${ }^{9}$, Armand Nkwesheu ${ }^{1}$, Mamie Bangonda ${ }^{7}$, Michel Noubom ${ }^{5,6}$, \\ François-Xavier Mbopi-Keou ${ }^{5,10}$
}

${ }^{1}$ Cameroon Society of Epidemiology, Yaounde, Cameroon

${ }^{2}$ School of Public Health, Texila American University, Georges Town, Guyana

${ }^{3}$ Provincial Division of Health Kasaï Oriental Province, Mbuji-Mayi, DRC

${ }^{4}$ Faculty of Medicine, University of Mbuji-Mayi, Mbuji-Mayi, DRC

${ }^{5}$ Ministry of Public Health, Yaounde, Cameroon

${ }^{6}$ Faculty of Medicine and Pharmaceutical Sciences, University of Dschang, Dschang, Cameroon

${ }^{7}$ WHE, World Health Organization, Kinshasa, DRC

${ }^{8}$ Ministry of Public health, Kinshasa, DRC

${ }^{9}$ National Institute of Biomedical Research, Kinshasa, DRC

${ }^{10}$ Faculty of Medicine and Biomedical sciences, University of Yaounde 1, Yaoundé, Cameroon

Email address:

flledongmo@yahoo.fr (N. T. Dongmo)

${ }^{*}$ Corresponding author

\section{To cite this article:}

Norbert Tanke Dongmo, Barry Mutombo, Jerome Ateudjieu, Gervais Folefack Tengomo, Mavard Kwengani, Paulin Gabo, Marie Claire Georgette Diwampovesa, Laurent Akilimali, Berthe Miwanda, Armand Nkwesheu, Mamie Bangonda, Michel Noubom, François-Xavier Mbopi-Keou. Cholera Outbreak in the Kasaï Oriental Province, Democratic Republic of Congo (DRC), 2018: The Case Fatality Rate in Mbuji-Mayi City and in the Rural Area. Science Journal of Public Health. Vol. 8, No. 1, 2020, pp. 8-18. doi: 10.11648/j.sjph.20200801.12

Received: February 7, 2020; Accepted: February 20, 2020; Published: March 2, 2020s

\begin{abstract}
Cholera remains the major public health problem in the world. Cholera is endemic in DRC especially in its east part. In the Kasai Oriental province, cholera is epidemic area which registered major epidemic cyclically with high case fatality rate. The last one in 2018 started in Mbuji-Mayi city but later affected the whole province during 45 weeks with 5854 total suspected cases registered including 277 deaths (CFR: 4.7\%). Our main objective was to describe this outbreak focusing on its higher CFR. We conducted quantitative descriptive study using data from the provincial line listing. Cholera was defined according to national and WHO case definition. Analyses were performed using Microsoft Excel 2010 and Epi-info7. Men were more affected (contracting or dying of) by cholera in the province. The proportion of men affected in rural area as well as the proportion of death was higher than in Mbuji-Mayi city. The outbreak started in Mbuji-Mayi with around CFR: 27.3\% as well as in the rural area with CFR: $23.5 \%$ after three weeks. CFR was also high among men in Rural area as well as among persons aged 15years and above. The remote health zone situated in rural area registered the highest CFR. These were Cilundu and Kabeya-Kamwanga.
\end{abstract}

Keywords: Cholera, Outbreak, Case Fatality Rate, Kasai Oriental, Democratic Republic of Congo 


\section{Introduction}

Cholera is a very contagious enteric disease caused by a gram negative and curved bacillus named Vibrio cholera. The disease is endemic in some part of the world mainly in SubSaharan Africans countries and is responsible for many outbreaks [1]. According to some studies the expected annually cholera cases estimation worldwide is between 1.3 to 4.0 millions of which 21,000 to 143,000 deaths [2]. These estimates are much higher than the data reported to WHO by different countries, which would therefore represent only 5$10 \%$ of actual cases and deaths worldwide. Hence a real under notification of this disease [2-4]. Cholera is mainly well established in the area that face certain challenges, such as development of water, hygiene and sanitation infrastructures, problems of promiscuity and poverty among populations, difficulties in accessing preventive and curative health services, including adequate immunization coverage for populations at risk [3-4]. Most of cholera deaths registered all over the world came from African countries. Indeed, in 2017, 80\% of cholera deaths were reported by three countries: Yemen, Somalia and Democratic Republic of Congo [5]. Cholera was introduced in Zaïre, now DRC, in 1974 [6]. Since then, the country has been experiencing recurrent cholera epidemics over the years and has even become one of the African countries with endemic cholera. Between 2013 and 2016, the country notified each year a means of nearly $34 \%$ of whole African cholera cases while a total African countries notified each year a mean of nearly $50 \%$ of cholera cases worldwide in the same period. The Eastern Provinces of the DRC in the Great Lakes Region, always reported the largest number of cholera cases in the country. Between 2002 and 2008, 66\% of cases and $71 \%$ of deaths reported occurred in the eastern DRC that means provinces of Katanga, South Kivu and North Kivu [7].

The Kasaï oriental (KOR) province, situated in the Centre part of the country faced probably its first cholera outbreak in 1992 but with no specific data are available [6]. The second cholera epidemic that affected this province was reported between September 2002-October 2004, a decade after the previous one [6]. This cholera outbreak started in the main city Mbuji-Mayi and during two years period, cumulated cholera cases of 9,767 including 571 deaths was registered with case fatality rate (CFR) of 5.8\% [6]. This was very high with regard to WHO standards $(\mathrm{CFR}<1 \%$, case management is correct). But when the CFR is high $(>1 \%)$, it always indicates poor health care management $[1,8,9]$ at the level of the Cholera Treatment Centres/Units (CTCs/UTCs) so we should check whether health care workers are well trained or not, if supplies or other cholera kit are lacking or not or if they are functioning correctly with sufficient, human, material and financial resources with regard to the number of cholera cases under treatment [10]. Higher CFR during cholera response should also indicated that people arrived too late at the CTCs/CTUs because of its accessibility or don't know their location. Finally a high CFR should be associated to the poor active cholera cases finding in classical health facility where they should be redirected to the very adapted CTCs/CTUs. But in certain critical conditions as during cholera outbreak of 1994 in refugee camps in the city of Goma, DRC following Rwandan genocide Goma, CFR can be highest, thus $69 \%$ [7]. On February, 12, 2018, in the $7^{\text {th }}$ epidemiological week (Week7), fourteen years after the 2002-2004 cholera outbreak in the KOR province, a new one was reported after stool samples collected from suspected cases from Diulu and Bonzola, two health zones (HZ) in the main city Mbuji-Mayi, were confirmed by the National Institute of Biomedical Research (INRB) in Kinshasa. This 2018 cholera outbreak finally affected the entire province and then spread all over the year, mobilizing human, material and financial resources. One of the major features of this outbreak was its high CFR, which in fact posed significant challenges in case management during this epidemic. The objective of this study was to describe the mains characterise this cholera outbreak focusing on its case fatality rate in link with some aspect of response intervention.

\section{Methods}

\subsection{Study Design}

Quantitative cross-sectional study for descriptive purposes was conducted to describe cholera outbreak with a focus in the case fatality rate.

\subsection{Study Area}

The KOR province, located in the center of the $\mathrm{DRC}$, is one of its 26 provinces since the configuration of 2015 [11]. With a population of $5,030,071$, it is one of the most populous provinces in the country. Its area is 9,699 kilometer square making it the smallest of the provinces in terms of area from which a relatively high density (504 inhabitants per kilometer square). Mbuji-Mayi, its main city is located in the center of the province occupying less than $10 \%$ of the entire provincial territory, but still hosts the majority $(60 \%)$ of the provincial population [12, 13]. This province is heavily irrigated by 3 major rivers: the Muya in the North; Kanshi in the South and Mbuji-Mayi in the East. In terms of health policy, the province is divided in 19 health zones (HZ), including $10 \mathrm{HZ}$ in the city of Mbuji-Mayi. But the health facilities and sanitations conditions in the province such as the installations structures in charge water supply are dilapidated. More ever, unemployment is endemic in the province [14, 15]. The abundance of diamond mines exploited in artisanal way for decades is a real boon of the poor populations who flock there massively creating very insanitary shantytowns, real factors of propagation of cholera [13].

\subsection{Period of Study}

The period of this study was the once concerned by data collection from the Week7 to Week52 of 2018. 


\subsection{Study Population}

Our target population consisted of all suspected cholera cases reported including deaths, residents in one of the 19 Health Zones (HZ) of the province including 10 from the city of Mbuji-Mayi and 09ZS from the rural part of the province. These suspected cases were regularly recorded in the line listing of each $\mathrm{HZ}$ and then regularly transmitted and compiled at the level of the Provincial Division of Health (DPS) by a data manager. After confirmation of cholera outbreak by the INRB laboratory, the notification of additional cases throughout the duration of the epidemic was made on the basis of the standardized definition of suspects cases in accordance with the directives in the matter $[1,5]$. Before performing analysis, we first cleaned up to eliminate all duplicates and then all suspected cholera cases residing outside the province a few days before and during their episode of diarrhea even if they were still undergoing their treatment in one of the health care center in the province.

\subsection{Some Key Definitions}

Cholera outbreak: Since KOR province is an epidemic area, a cholera outbreak is confirmed there when a single suspected watery diarrhea meeting suspected case's definition was confirmed in National Laboratory INRB.

Case definition: A suspected cholera case was a resident of KOR province during the study period, regardless of age, with profuse watery diarrhea with or without dehydration (three or more stool within 24 hours) or anyone who died of diarrhea $[8,9]$.

A confirmed cholera case was a suspected case with confirmation of the isolation of Vibrio cholerae $\mathrm{O} 1$ or $\mathrm{O} 139$ in stool by culture INRB.

CFR (\%): Number of deaths attributable to cholera registered in one of the $19 \mathrm{HZ}$ of the KOR province during the period of the epidemic x 100 / Number of cases notified of death of cholera in the same area, in the same period.

\subsection{Data Analysis}

The data in the updated line-listing, available on a Excel file, were firstly analyzed with Microsoft Excel software to generate graphs and then were imported into Epi-Info7 of $\mathrm{CDC}$ for certain frequency and tables analyzes.

\subsection{Ethical Consideration}

Not applicable as this study was conducted using secondary data.

\section{Results}

The cholera outbreak reached the KOR province through the city of Mbuji-Mayi. The index case was a 35-year-old woman who returned the day before from neighboring Lomani province after attending a funeral. Lomami province was affected by a big the wave of cholera outbreak that affected DRC in 2017 and was still in ongoing for several months. This KOR cholera outbreak was confirmed by the isolation of Vibrio cholerae $\mathrm{O} 1$ at the National Laboratory of the INRB in Kinshasa in the Week7 of 2018 and since the till Week52 of 2018, a total of 5,869 were reported after the linelisting was completely cleaned. Sixteen suspected cases misclassified in the Province were excluded for the purpose of analysis. Thus, a total of 5854 suspected cases including 277 deaths (CFR: 4.7\%) were recorded across the province

\subsection{Cases and Deaths Reported in the KOR Province}

\subsubsection{Sex of Cases and Deaths Reported}

In the whole province, $51.0 \%(2985 / 5854)$ of reported cases were male. In Mbuji-Mayi city, approximately $50 \%$ of reported cases were men meanwhile in the rural area, $52.2 \%$ of reported cases were men. (Figure 1).

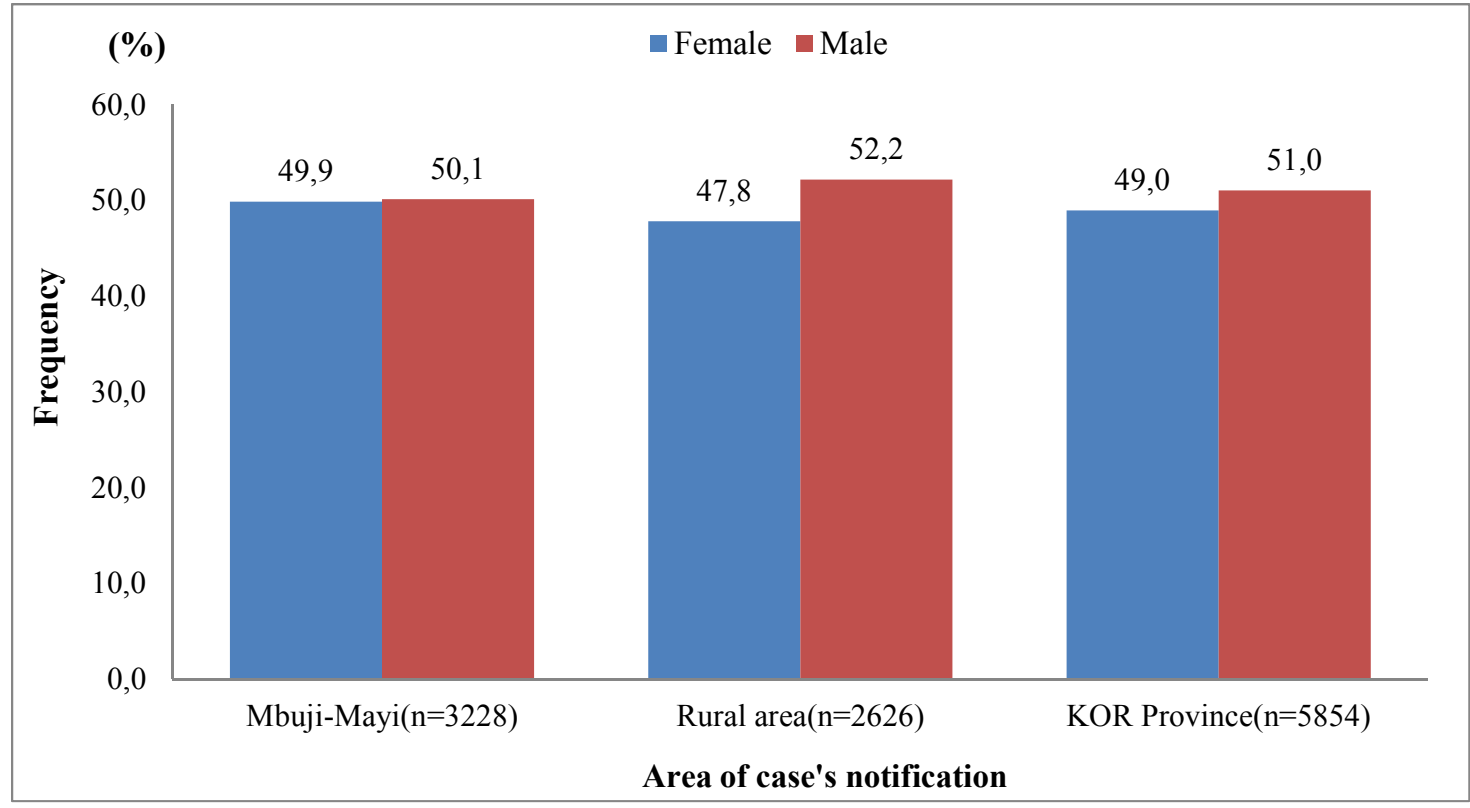

Figure 1. Distribution of suspected cholera cases by sex and area of notification, KOR province, RDC, Week7-Week52, 2018. 
As cholera death id concerned, of a total of 277 registered deaths reported in the KOR province, 151 (54.5\%) were male. While male are $53.5 \%$ of total deaths reported in Mbuji-Mayi city, 55.6\% of deaths were reported in the rural area (Figure 2).

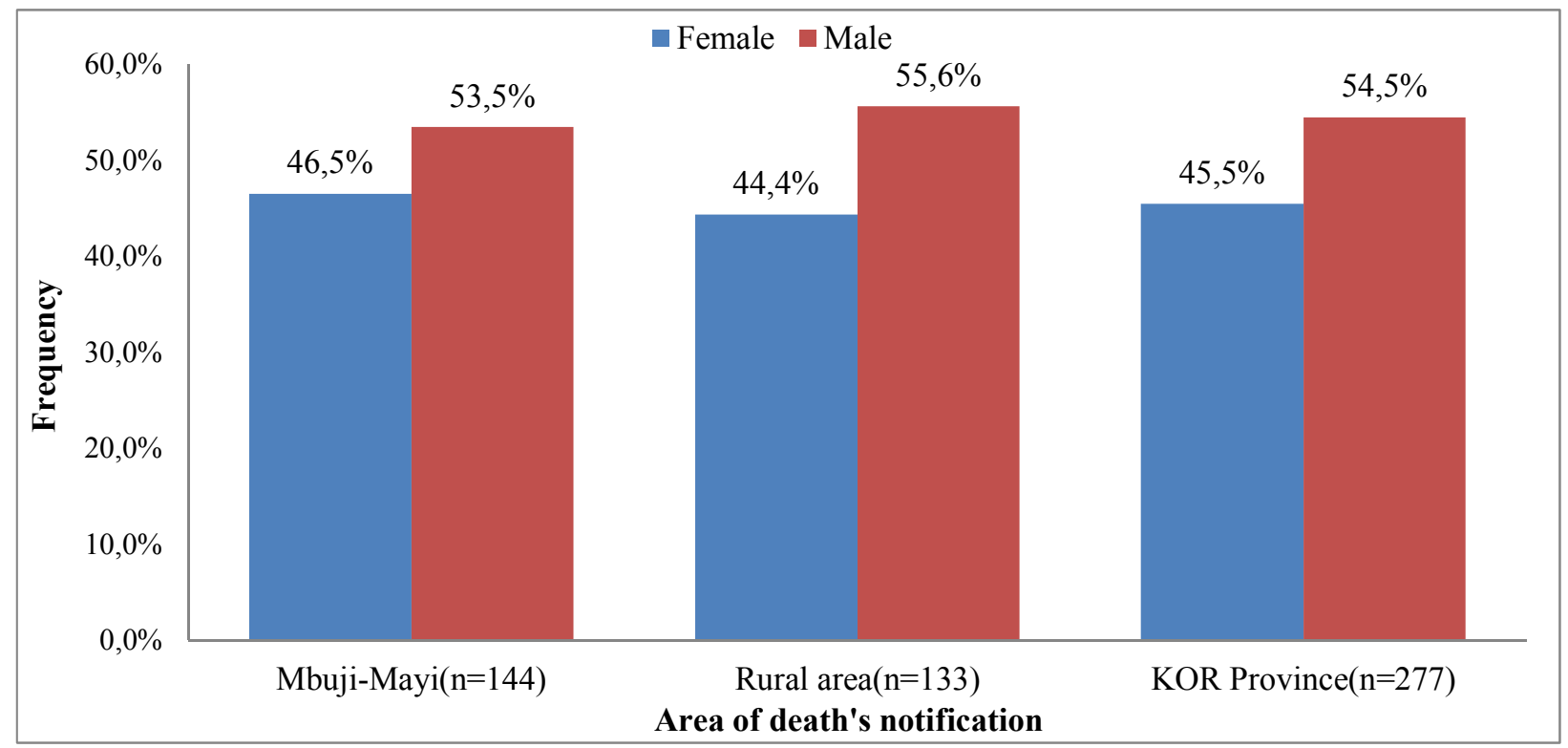

Figure 2. Distribution of cholera related deaths cases by sex and area of notification, KOR province, RDC, Week7-Week52, 2018.

\subsubsection{Age of cholera cases and deaths.}

Out of a total of 5854 suspected cholera cases reported in the province, $73.1 \%(4290 / 5854)$ were aged 15 years and above. This proportion of aged 15 and above was lower (70.1\%) among cases notified in the city of Mbuji-Mayi; but higher (77.2\%) among cases notified in the rural part of the country (Figure 3).

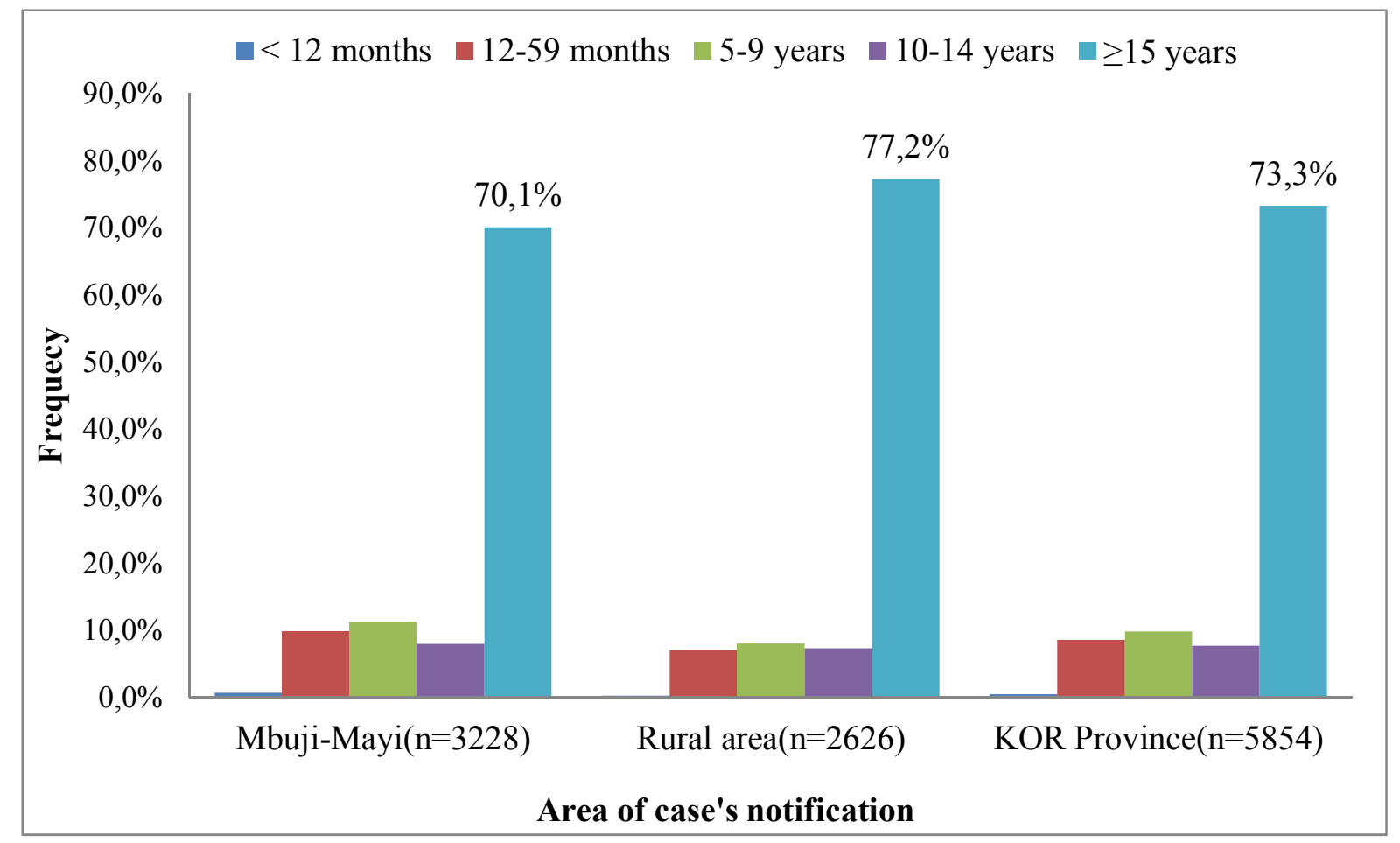

Figure 3. Distribution of suspected cholera cases by age and area of notification, KOR province, RDC, Week7-Week52, 2018.

As for registered cholera deaths, of the 277 reported in the province, 84.1\% (233/277) were aged 15 and above. This proportion of deaths among those aged 15 and above was nevertheless higher $(85.7 \%)$ among the cases notified in the rural part of the province but lower (82.6\%) among those notified in the city of Mbuji-Mayi (Figure 4). 


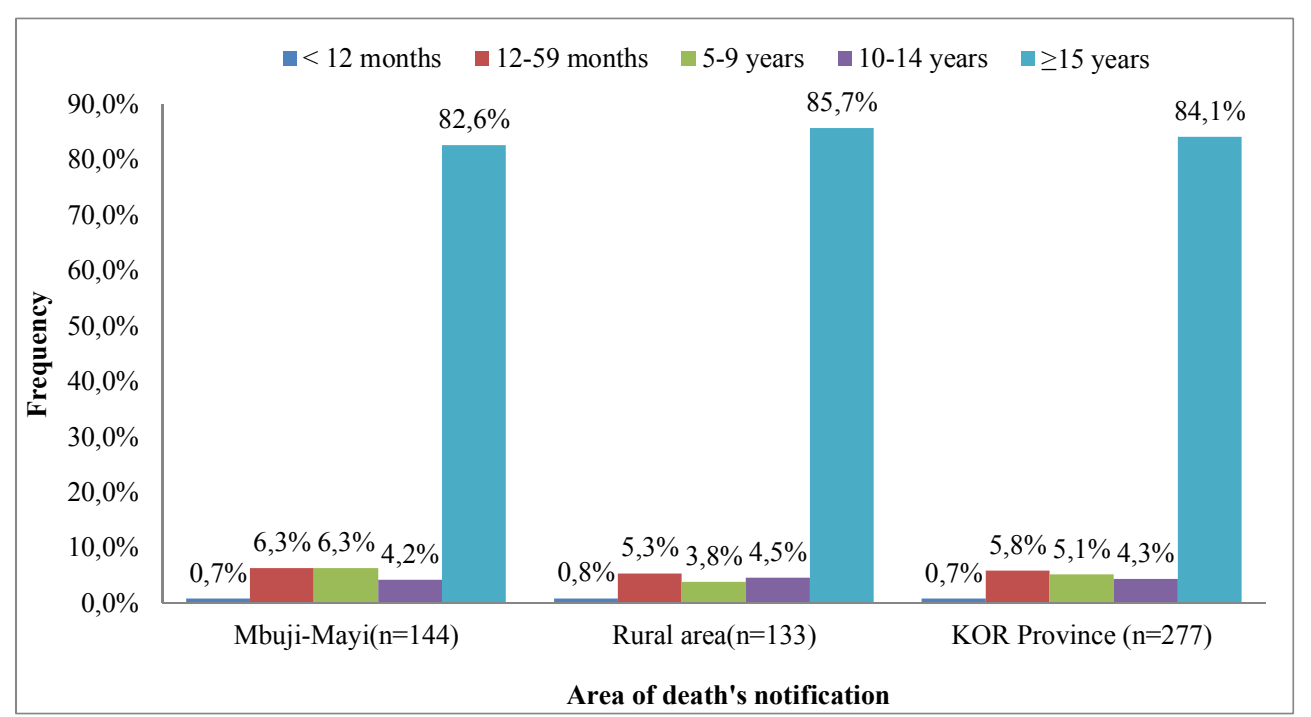

Figure 4. Distribution of cholera related deaths by sex and area of notification, KOR province, RDC, Week7-Week52, 2018.

\subsection{Epidemic Curve and CFR During Cholera Outbreak in KOR Province}

Putting side by side, the epidemic curve in the KOR province (Figure 5), the epidemic curve in the city of Mbuji-Mayi (Figure 6) and the epidemic curve in the rural part of the province (Figure 7), we could made some major observations to better understand certain evolutions of the outbreak as well as of its CFR.

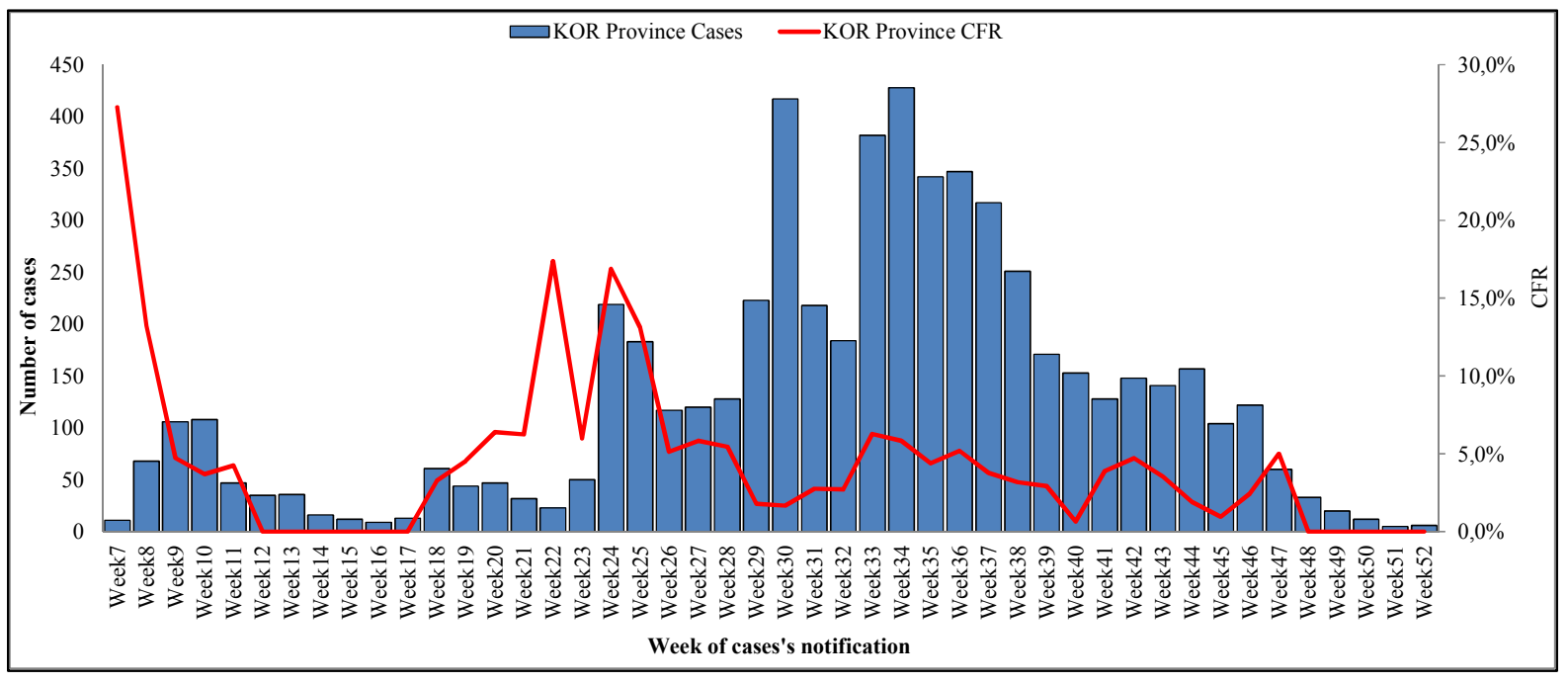

Figure 5. Weekly evolution of suspected cholera cases and CFR in KOR province, DRC, 2018.

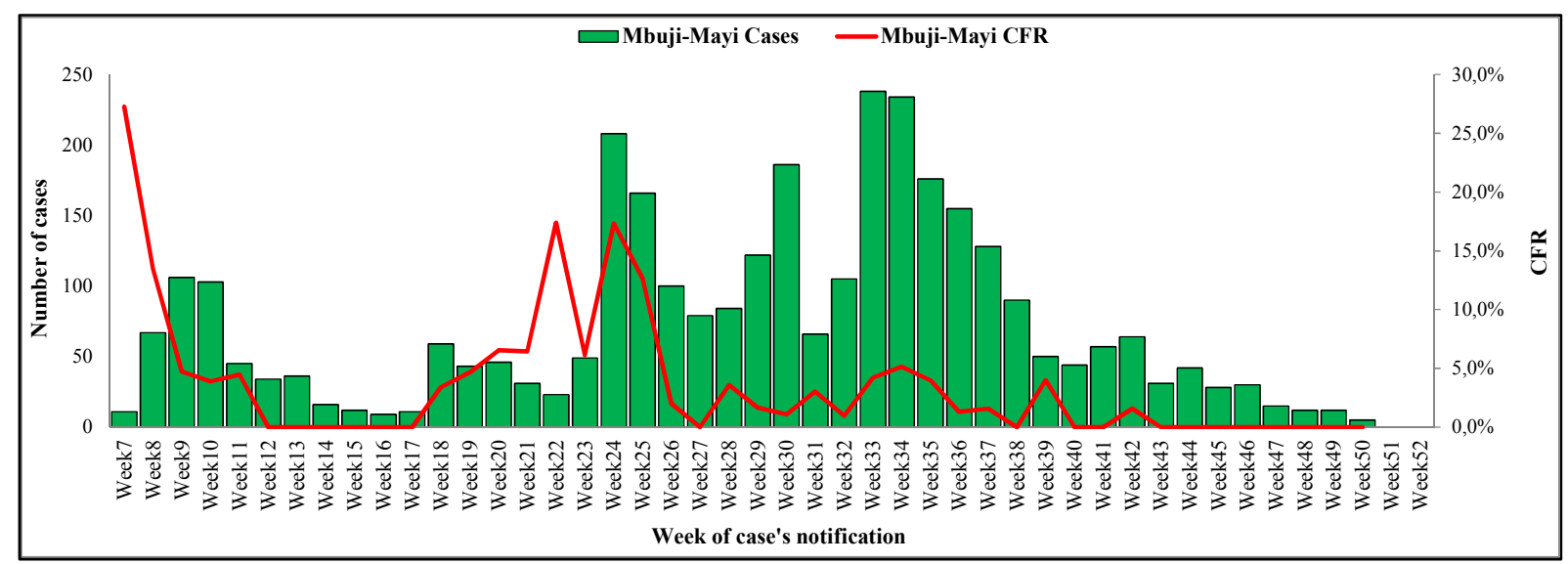

Figure 6. Weekly evolution of suspected cholera cases and CFR in Mbuji-Mayi city, DRC, 2018. 


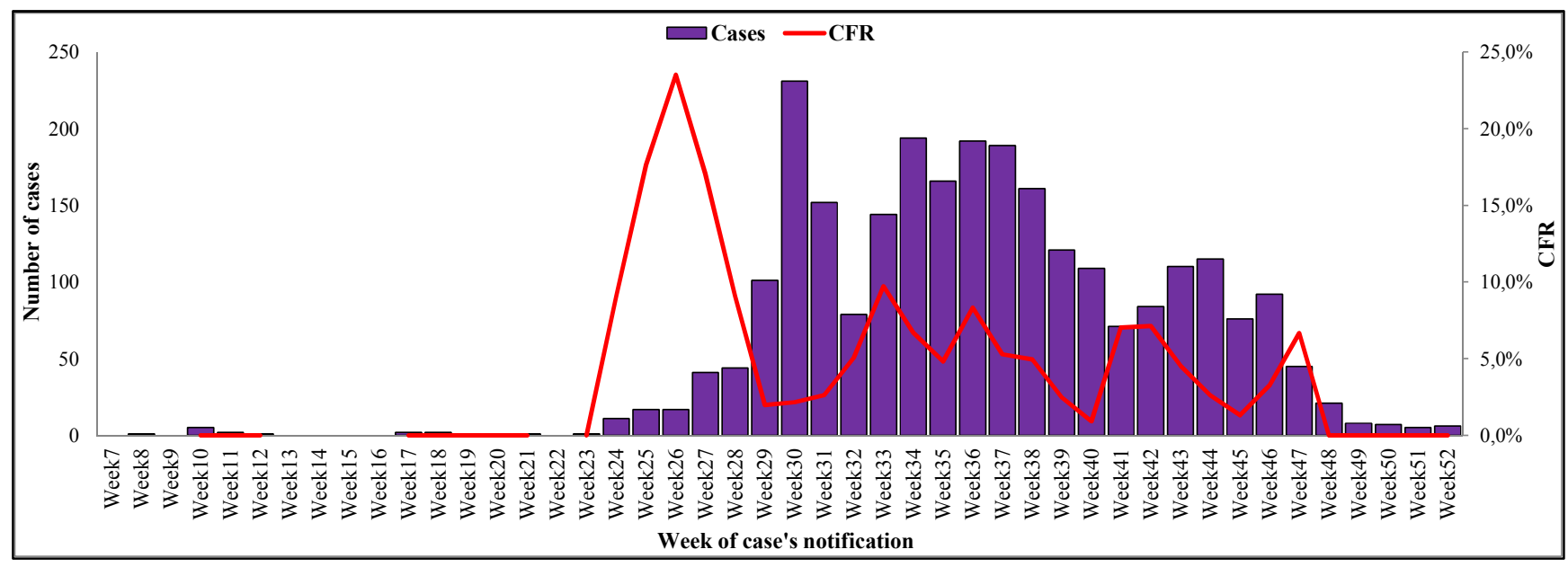

Figure 7. Weekly evolution of suspected cholera cases and CFR in Rural area of KOR, DRC, 2018.

From Week 7 to Week24 of 2018, the cholera outbreak started and was confined only in Mbuji-Mayi city even though rare but non-confirmed cases were registered in the rural part of the province in the same period of time. We should noticed that on this single Week24, 219 cases including 37 death (CFR: 17\%), it was in that moment the highest peak of the outbreak, observed after 18 weeks of riposte interventions in Mbuji-Mayi.

It was probably on this Week24, that many people coming from the rural part of the province, arrived in Mbuji-Mayi city, either to take care of their relatives affected by cholera or to assist them at the funeral (34 cholera deaths registered in a single week) that cholera was brought and spread to the rural part of the province.

Another major observation made when analysing these three epidemic curves is that, following the critical situation of the week24 in Mbuji-Mayi, cholera response was boosted in the city. This is the reason why we noticed a rapid decrease of cases and the CFR during week25, week26 and week 27. But the disease was already spreading in the rural part of the province with a maximum of $23.7 \%$ CFR in week 26 .

From the Week 24 practically until the end of the year, the cholera outbreak raged throughout the province (simultaneously in Mbuji-Mayi city and in the rural part of the province) ultimately affecting all 19 Health zones and remains until the end of 2018.

This cholera outbreak started in Mbuji-Mayi city at Week7 with a very high CFR of $27 \%$ (Figure 6) and similarly, Week24 marked the beginning of the cholera spreading in the rural part of the province with ones more a high CFR increasing from $9 \%$ to $24 \%$ in week 26 (Figure 7 ).

These CFR registered at the beginning of the cholera outbreak in Mbuji-Mayi as in the rural part of the province generally decreased with some oscillation within the response activities on the field, but nevertheless remained higher in rural areas than in the city of Mbuji-Mayi, although overall remained well above the acceptable WHO standard $(\mathrm{CFR}<1 \%)[1]$.

\subsection{CFR by Sex and Area of Residence of Cases}

The overall CFR in the KOR province was high (5.1\%) among men in the rural part of the province than among women $(4.4 \%)$. The proportion men dying of cholera in rural area was high $(5.4 \%)$ than the proportion of men dying of cholera in Mbuji-Mayi city (4.8\%) in all situations, men were still more fatally affected than women (Table 1).

Table 1. CFR during cholera outbreak in KOR province, DRC, 2018 (according to sex and area of residence).

\begin{tabular}{|c|c|c|c|c|c|c|c|c|c|}
\hline \multirow{2}{*}{$\begin{array}{l}\text { Locality/area } \\
\text { Sex }\end{array}$} & \multicolumn{3}{|c|}{ Mbuji-Mayi } & \multicolumn{3}{|c|}{ Rural area } & \multicolumn{3}{|c|}{ KOR Province } \\
\hline & Deaths & Cases & CFR & Deaths & Cases & CFR & Deaths & Cases & CFR \\
\hline Female & 67 & 1610 & $4,2 \%$ & 59 & 1256 & $4,7 \%$ & 126 & 2866 & $4,4 \%$ \\
\hline Male & 77 & 1618 & $4,8 \%$ & 74 & 1370 & $5,4 \%$ & 151 & 2988 & $5,1 \%$ \\
\hline Total & 144 & 3228 & $4,5 \%$ & 133 & 2626 & $5,1 \%$ & 277 & 5854 & $4,7 \%$ \\
\hline
\end{tabular}

\subsection{CFR by Age and Area of Residence}

CFR in the province was higher (6.7\%) among aged less than one year. In Mbuji-Mayi city, CFR was higher (5.3\%) among those aged 15 years and above while in the rural part of the province, CFR was higher (14.3\%) among those aged less than one year. (Table 2). 
Table 2. CFR age and area of residence during Cholera outbreak in KOR province, DRC, 2018.

\begin{tabular}{llllllllll}
\hline Area & Mbuji-Mayi & \multicolumn{3}{c}{ Rural area } & \multicolumn{3}{c}{ KOR Province } \\
\hline Age Group & Deaths & Cases & CFR & Deaths & Cases & CFR & Deaths & Cases & CFR \\
\hline$<12$ months & 1 & 23 & $4,3 \%$ & 1 & 7 & $14,3 \%$ & 2 & 30 & $6,7 \%$ \\
$12-59$ months & 9 & 319 & $2,8 \%$ & 7 & 186 & $3,8 \%$ & 16 & 505 & $3,2 \%$ \\
$5-9$ years & 9 & 365 & $2,5 \%$ & 5 & 212 & $2,4 \%$ & 14 & 577 & $2,4 \%$ \\
$10-14$ years & 6 & 259 & $2,3 \%$ & 6 & 193 & $3,1 \%$ & 12 & 452 & $2,7 \%$ \\
$\geq 15$ years & 119 & 2262 & $5,3 \%$ & 114 & 2028 & $5,6 \%$ & 233 & 4290 & $5,4 \%$ \\
Total & 144 & 3228 & $4,5 \%$ & 133 & 2626 & $5,1 \%$ & 277 & 5854 & $4,7 \%$ \\
\hline
\end{tabular}

\subsection{CFR by Area of Residence and by $\mathrm{HZ}$.}

CFR ranged from $1.9 \%$ to $15.3 \%$ in all the $9 \mathrm{HZ}$ of the rural part of the province, with an overall CFR of $5.1 \%$. In MbujiMayi city, CFR ranged from $1,0 \%$ to $9.4 \%$, in all the $10 \mathrm{HZ}$, with an overall CFR of $4.5 \%$ (Figure 8 ).

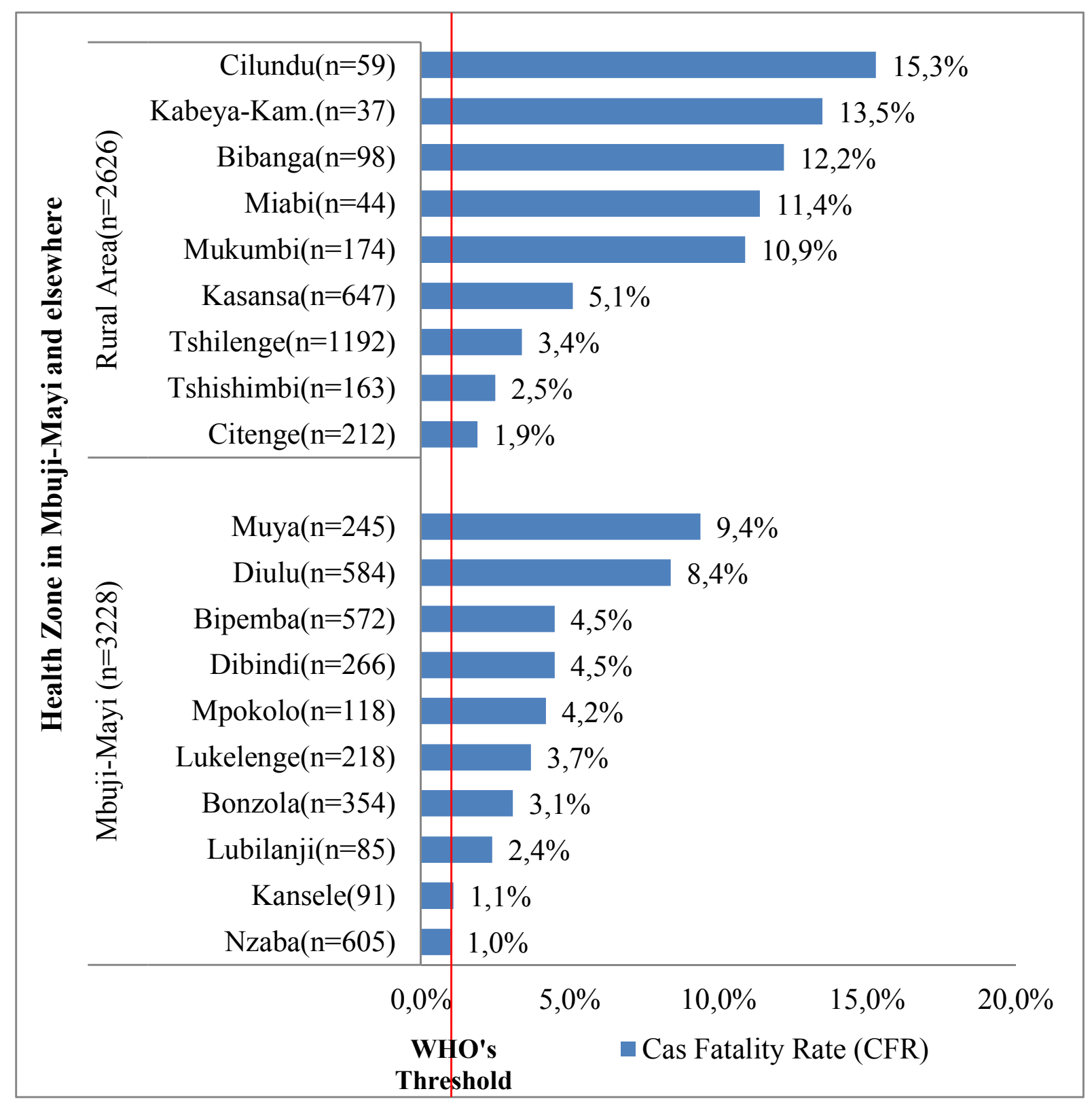

Figure 8. CFR in $19 \mathrm{HZ}$ during cholera outbreak in KOR province, DRC, 2018

We should also see a mapping of CFR distribution within the KOR Province below in Figure 9. 


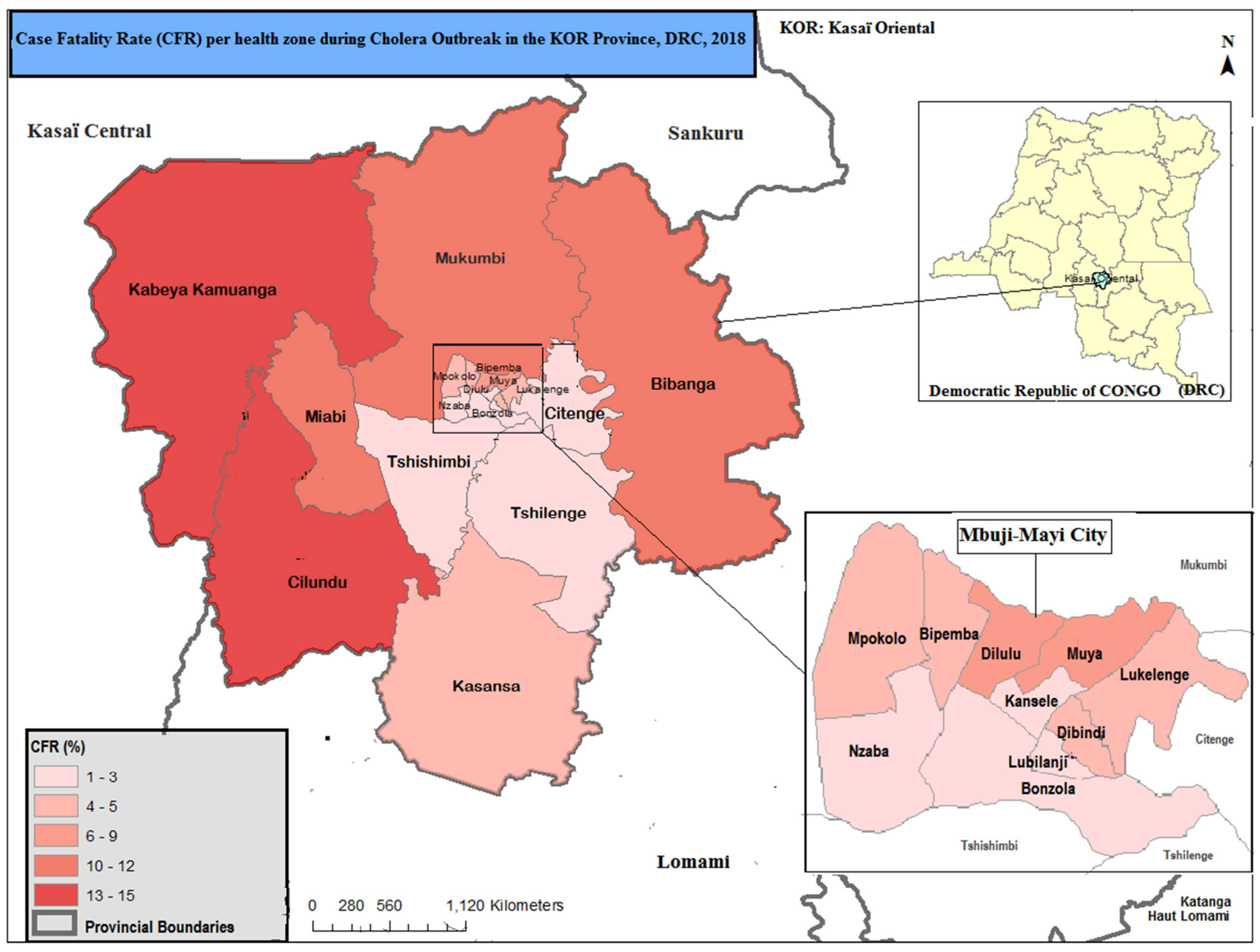

Figure 9. Mapping of CFR distribution per Health Zone in the province of KOR, DRC, 2018.

\section{Discussion}

The confirmation of this second major cholera outbreak in the KOR province was made on the Week7 when INRB isolated Vibrio cholera serogroup $\mathrm{O} 1$ in the stools of suspected cases. The biotype and serotype were not available, but these two additional steps in identifying $V$. cholerae are not essential for the field management of a cholera epidemic or outbreak [7]. This 2018 cholera outbreak KOR province was the one with the second highest CFR $(4.7 \%)$, fourteen year after the (2002-2004) cholera outbreak which had an overall CFR of around 6\%. The 2018 cholera outbreak entered the province through its eastern boundary, notably through the province of Lomami, which already faced at that moment cholera outbreak for several months. The index case went there for the burial of a member of her family. Indeed, funerals are one of the factors of cholera dissemination in African countries as it was observed in Kenya [6, 16, 17].

Men $(51.0 \%)$ were more affected by cholera than women in KOR province. In the rural part of the province, they were even more affected (52.2\%) than in Mbuji-Mayi city $(50.1 \%)$. This can be explained by the fact that men were more to migrate towards the artisanal mining sites which are dispersed in many part of rural health zones such as in Tshillenge and Tshishimbi. They do it for economic reasons
[18]. More ever, $54.5 \%$ of all deaths in the province were among men. In the rural part of the province, the proportion of death among men was even higher $(55.5 \%)$ than in the city of Mbuji-Mayi (53.5\%). This can be explained by the fact that in rural areas, men generally during their field work in the mines or in farms eat occasionally and only when the meal is available. This is not the case for women who, by virtue of their responsibilities to feed the family, have regular food. So, knowing the role of food and the immune system in the severity of cholera [8], such situation is understandable.

A large proportion of the cases $(73.1 \%)$ reported in the KOR province were aged 15 and above. In the rural part, this proportion of those aged 15 and above was even higher (77.2\%). This shows that the contamination and dissemination of the disease occurred in places where there were high concentrations of adolescents and adults, which mean the very active population. A study conducted in Cameroon also found that the adult population was the most affected by cholera [19]. Indeed, if the source of contamination was common to all populations ages, such as a public water pump or a contaminated food sold in the market of Mbuji-Mayi city for example, the consequence should have been that all age groups were affected. We also noticed that CFR was high among children less than 1 year in the rural area $(14.3 \%)$ than in Mbuji-Mayi $(4.3 \%)$ This can be explained by the fact that in the rural area, the mastering of 
case definition could have been weak. So they registered all infants diarrhea was probably notified as cholera. But it is well known that at this this age; many cases of watery diarrhea from other causes as rotavirus, Escherichia coli and salmonella or even nutritional can kill the babies [10].

In addition, $84.1 \%$ of deaths recorded in the province were among the 15 years and above, while in deaths recorded in Mbuji-Mayi city, the proportion of 15 years and above was lower $(82.6 \%)$ But in the rural part of the province, $85.7 \%$ of recorded deaths was aged 15 years and above.

Cholera epidemics used to start with high CFR [5, 9]. This was also seen at the beginning of this epidemic in the city of Mbuji-Mayi (CFR: 26\%); but also at the cholera epidemic started in the rural part of the province with a high (CFR: $23 \%$ ). The decline in CFR that generally follows is the result of the progressive installation of more suitable structures of case management such as CTCs, CTUs and Oral Rehydration solution points (ORSP). Similarly, the trends of rising CFR or oscillations observed in figures 5, 6 and 7 can be explained either by explosion of cases in newly affected area where CTCs/CTU which are not yet in place, or by a decrease or shortcomings in the case management in the existing structures [10]. In view of this CFR which remained for a long time above $5 \%$, the Provincial Crisis Committee (CPC) with the support of its technical partners at the forefront of which the National Program for the Elimination of Cholera (PNECHOL-MD), WHO, UNICEF, OCHA and MSF created new CTCs/CTUs, as well as many OSRP, especially in the rural part of the province, which generally has less healthcare infrastructure. Organized training sessions, Supplied drug kits and Wash kits, recommended free of charge healthcare and reinforced provided financial motivation of the CTCs/UTCs/ORSP staff as well as the meal provided to all sick patients. Despite all of these, CFR remained well above $1 \%$ which meant that some challenges in case management still remained. It was not until the Week48 of 2018 that this challenge was met in the province with a sporadic notification of case and CFR of $0 \%$.

None of the $19 \mathrm{HZs}$ in the province had a CFR of less than $1 \%$ (WHO Standard for Case Management during the Cholera Epidemic). But however, certain epidemics recorded in Africa, particularly in South Africa and in Benin succeeded to report CFRs of less than 1\% [20-21], The overall CFR in the province during this cholera epidemic was $4.7 \%$, but was higher in the rural part of the province (CFR: $5.1 \%$ ) and slightly lower in the city of Mbuji-Mayi (CFR: 4.5\%). This was explained by the relative proximity of Mbuji-Mayi's populations to the provincial coordination of the cholera response, the headquarter of all provincial institutions as well as technical and financial partners are in Mbuji-Mayi; most of the referral healthcare structures in the province are located in this city, some of which could easily and quickly be transformed into CTCs or CTCs like the CTC installed at Bipumba General Hospital. Another reason is that since the city of Mbuji-Mayi is not very large or landlocked, populations seeking for healthcare could relatively easily reach the $\mathrm{CTC} / \mathrm{CTU}$ of their choice. Similar higher CFR was also reported in certain epidemics in Nigeria [22] and in Zimbabwe [23-24]. On the other hand, in the rural areas, once there is cases explosion somewhere, everything had to be built, in the area which sometimes faced difficulties of access, even with robust cars. Hence the possibility of input shortages in case management center that could lead to more deaths. In addition, when CTCs/CTUs were built, there were sometimes very in very remote area. Similar situations have been described by in Haiti [25]. Up to a time, the only created CTCs/CTUs were located in Mbuji-Mayi city and around (example of UTC, Luamuela, HZ Tshilenge). With the single ambulance responsible for transporting cases, some cases died in community or during their transportation due to long waits. As solutions later, additional CTCs/CTUs were created all in the rural part of the Province ( 02 in Kasansa and one in Mukumbi) as well as the multiplication of ORSP. It should be noted that even higher CFRs such as those found in very isolated rural $\mathrm{HZs}$ have been reported in rural localities of Africa as during the in Kenya [17] and in Haiti [25]. In the city of Mbuji-Mayi and its $10 \mathrm{HZ}, \mathrm{CFR}$ varied according to the Health zones affected lethality from $1 \%$ to $9.4 \%$ against $1.9 \%$ to $15.3 \%$ in the $9 \mathrm{HZ}$ of the rural part of the province. Note that the most isolated parts of the province, fortunately less affected by the cases like KabeyaKamwanga and Cilundu recorded the highest CFR.

\section{Limitations}

CFR in this study was particularly high. It may have been over estimated for several reasons. The first reason to underline is the case definition used which included all age's group. But it's well known that in population of less than five years old, many cases of diarrhea may not be cholera. But this statement was not important in our study since in cholera cases notified, only $9 \%$ were ages less than five. The second point also related to the case definition is that, registering cases only on the clinical suspicion without laboratory confirmation, as mentioned above, others diarrhea from other sources may be registered as cholera. In addition, during cholera response, all death related to cholera should be managed and secured by the response team with many aspect free of charge. In an environment of poverty, it is possible that, some family members or relatives declared as cholera deaths some death that may have been for others causes.

\section{Conclusion}

This 2018 cholera outbreak which started affecting the KOR province in Mbuji-Mayi city before spreading to its rural part finally affected the entire province for 45 weeks, mobilizing important human, material and financial resources. One of the major information during this epidemic was its very high global CFR, which put on the light the significant challenges on case management faced during this cholera outbreak as it is often found in developing countries, specifically in sub-Saharan Africa where cholera is endemic. All the $19 \mathrm{HZ}$ registered high CFR $(>1 \%)$ but the highest 
CFRs were found in the rural part of the province, especially in the most landlocked HZ. CFR were also highest among men and patients aged 15 years and above.

\section{Acknowledgements}

Our thanks go to all the personnel of the Provincial Division of Health of the KOR province in Mbuji-Mayi, and their technical partners namely, WHO, Unicef, OCHA, MSF, AIDES, Save the children without forgetting our biostatitician Mr. Abdoulaye Sinayoko.

\section{References}

[1] WHO: World Health Organization, 2004, Cholera Outbreak: Assessing the Outbreak Response and improving preparedness, Global Task Force for cholera control. Retrieved in December 2, 2019 from https://www.who.int/cholera/publications/final\%20outbreak\% 20booklet\%20260105-OMS.pdf.

[2] Ali M, Nelson AR, Lopez AL, Sack D., 2015, Updated Global Burden of Cholera in Endemic Countries; PLoS Negl Trop Dis 9 (6): e0003832. doi: 10.1371/journal.pntd.0003832.

[3] WHO: World Health Organization, 2017, Vaccins anticholériques: note de synthèse de l'OMS -Août 2017.

[4] GTFCC: Global Task Force on Cholera Control, 2017, Ending Cholera - A Global Roadmap to 2030. 32p Retrieved in December, $2, \quad 2019$ from https://www.who.int/cholera/publications/globalroadmap.pdf?ua $=1$.

[5] WHO: World Health Organization, 2018, Le cholera: Norme de Surveillance des maladies évitables par la vaccination. dernière mise à jour le 5 septembre 2018, Online https://www.who.int/immunization/monitoring_surveillance/b urden/vpd/WHO_SurveillanceVaccinePreventable_02_Choler a_French_R1.pdf?

[6] Bompangue D., 2009, Dynamique des épidémies de choléra dans la région des grands lacs africains: cas de la République Démocratique du Congo, Thèse de Doctorat en Sciences de la vie et de la santé, Université de Franche-Comté, France, $265 \mathrm{pp}$.

[7] Bompangue Nkoko, D., Giraudoux, P., Plisnier, P., Tunda, A. M., Piarroux, M., Sudre, B., Horian, S., Tamfum, J. M., Ilunga, B. K., Piarroux, R., 2011, «Dynamics of cholera outbreaks in Great Lakes Region of Africa, 1978-2008,» Emerging Infectious Diseases, vol. 17, $\mathrm{n}^{\circ} 11$.

[8] CDC: Center for Disease Control and Prevention, nd, Cholera Vibrio cholarea infection, consulted on the November 202019 online https://www.cdc.gov/cholera/diagnosis.html.

[9] MSF: Médecins Sans Frontières, 2018, Management of an cholera epidemiie, Practical guide for doctors, nurses, laboratory technicians, health auxiliaries, health technicians and logisticians; 2018 Edition, Retrieved in December 2, 2019 from https://medicalguidelines.msf.org/msf-bookshosting/23444436-Francais.pdf.

[10] WHO: World Health Organization, nd, Prevention and control of cholera outbreaks: WHO policy and recommendations,
Global Task Force on Cholera Control, consulted on September, $\quad 12, \quad 2019 \quad$ Online http://www.who.int/cholera/technical/prevention/control/en/in dex.html.

[11] Congo Profond, 2018, Présentation de la province du Kasaï Oriental, Zoom sur l'autre Congo oublié, consulté le 12/12/2019 Online https://congoprofond.net/presentation-dela-province-du-kasai-oriental/.

[12] DPS: Division Provinciale de la Santé du Kasaï Oriental, 2018, Annual Report of the PDH of Kasai Oriental Province, Mbuji-Mayi, DRC 2017 Exercise, 35p.

[13] DPS: Division Provinciale de la Santé du Kasaï Oriental, 2019, Epidemic Emergency Preparedness Plan: 2019, MbujiMayi, DRC; 25p.

[14] PNUD: Programme des Nations Unies pour le Développement Unité de lutte contre la pauvreté, Mars (2009), Unité de lutte contre la pauvreté, Province du KOR, Profil résume, Pauvrete et conditions de vie des menages. May, 22, 2019 online http://www.ipamec.be/Documents/Profil_kasai\%20oriental_fi nal.pdf.

[15] Shomba K. S. and Olela N. N., 2015, Monograph of the city of Mbuji-Mayi, CRDI, Ed. MES. 104P. Retrieved on December, 72019 from https://www.idrc.ca/sites/default/files/sp/Documents\%20EN/ Monographie.pdf.

[16] Shapiro RL, Otieno MR, Adcock PM et al., 1999. Transmission of epidemic Vibrio cholerae O1 in rural western Kenya associated with drinking water from Lake Victoria: an environmental reservoir for cholera? Am J Trop Med Hyg. 60 (2): 271-276. PubMed | Google Scholar.

[17] Onyango D., Karambu S., Abade A., Amwayi S., and Omolo J., (2012), High case fatality cholera outbreak in Western Kenya, August 2010; The Pan African Medical Journal., retrieved from https://www.ncbi.nlm.nih.gov/pmc/articles/PMC3828060/.

[18] Unicef; 2013, Guide pratique de lutte contre le choléra de l'UNICEF, Retrieved from https://www.unicef.org/french/cholera_toolkit/Document_prin cipal_guide_pratique_de_lutte_contre_le_cholera.pdf.

[19] Nsagha DS., Atashili J., Fon NP., Tanue EA., AyimaCW and Kibu OD; (2015), Assessing the risk factors of cholera epidemic in the Buea Health District of Cameroon, BMC Public Health, 15: 1128. DOI 10.1186/s12889-015-2485-8.

[20] Kazaji DK. (2016), Factors contributing to the prevalence of cholera during 2008 to 2009 in Vhembe District of Limpopo province, south Africa, Master of Public Health, University of Limpopo, South Africa, Retrieved from https://pdfs.semanticscholar.org/5f76/ca905aa568c8b87d4d3a $3 \mathrm{e} 3 \mathrm{a} 3 \mathrm{c} 5448 \mathrm{db} 0 \mathrm{fcf} . \mathrm{pdf}$.

[21] Gbary AR., Roch Sossou A., Dossou JP., Mongbo V. \& Massougbodji A., (2011), Les déterminants de la faible létalité de l'épidémie de choléra dans le littoral au bénin en 2008, S. F. S. P, 23 (5): 345-358. Retrieved on December, 10, 2018 from https://www.cairn.info/revue-sante-publique-2011-5-page345.htm.

[22] Adagbada AO., Adesida SA., Nwaokorie FO., Niemogha MT., Coker AO., 2012, Cholera Epidemiology in Nigeria: an overview, Pan Afr Med J. 2012; 12: 59. Online https://www.ncbi.nlm.nih.gov/pmc/articles/PMC3428179/. 
[23] Dubois A. E., Sinkala M., Kalluri P., Makasa-Chikoya3 M. and Quick E., 2006, Epidemic cholera in urban Zambia: hand soap and dried fish as protective factors, Epidemiol. Infect. 134, 1226-1230. On May 2018 doi: $10.1017 / \mathrm{S} 0950268806006273$.

[24] Morof D., Cookson ST., Laver S., Chirundu D., Desai S., Mathenge P., Shambare D., Charimari L., Midzi S., Blanton C., and Handzel T., (2013), Community Mortality from
Cholera: Urban and Rural Districts in Zimbabwe, Am. J. Trop. Med. Hyg., 88 (4): 645-650 Doi: 10.4269/ajtmh.11-0696.

[25] Page A-L, Ciglenecki I, Jasmin ER, Desvignes L, Grandesso F, Polonsky J, et al., (2015), Geographic Distribution and Mortality Risk Factors during the Cholera Outbreak in a Rural Region of Haiti, 2010-2011. PLoS Negl Trop Dis 9 (3): e0003605. doi: 10.1371/journal.pntd.0003605. 